\title{
ACHADOS SOBRE A NOÇÃO ARQUEOLÓGICA DO DISCURSO EM FOUCAULT
}

\author{
Erenildo João Carlos ${ }^{1}$
}

\begin{abstract}
RESUMO
O intuito deste texto é o de registrar alguns achados e reflexões sobre o modo arqueológico como Foucault analisou a questão do discurso. A fonte primária deste estudo são os próprios escritos de Foucault, precisamente, os das décadas de sessenta e setenta. O percurso que empreendo assenta-se na perspectiva analítico-argumentativa, que, por causa da escavação dos enunciados sobre o assunto, busca descrever o entendimento arqueológico de Foucault sobre o discurso, o que, a meu ver, operou um deslocamento do signo, tradicionalmente linguístico e semiótico, para o discursivo-enunciativo. Esse movimento é o que denomino de giro arqueológico, fundamental para se entender a abordagem da Análise Arqueológica como uma Teoria do Discurso.
\end{abstract}

Palavras-chaves: Análise Arqueológica do discurso. Foucault. Discurso.

\section{FINDINGS ABOUT THE ARCHAEOLOGICAL NOTION OF THE SPEECH IN FOUCAULT}

\begin{abstract}
The purpose of this text is to record some findings and reflections on the archaeological way as Foucault analyzed the discourse issue. The primary source of this study is Foucault's own writings, precisely those of the sixties and seventies. The course I undertake is based on the analytic-argumentative perspective, which, due to the excavation of the statements on the subject, seeks to describe Foucault's archaeological understanding of the discourse, which, in my view, operated a displacement of the sign, traditionally Linguistic and semiotic, to the discursive-enunciative. This movement is what I call the archeological meander, fundamental to understanding the approach of Archaeological Analysis as a Discourse Theory.
\end{abstract}

Key-words: Analysis Discourse Archaeological. Foucault. Speech.

\section{INTRODUÇÃO}

O intuito deste texto é o de registrar algumas reflexões sobre o modo arqueológico como Foucault tratou a questão do discurso. Restringirei a discussão sobre certos aspectos, entre a vasta gama de possibilidades que seu legado abarca e o rico e relevante acervo de contribuições que ele deixou para o campo das humanidades e para os efetivos estudos, as investigações e as pesquisas empreendidas no terreno do discurso, como as análises arqueológicas do discurso - AAD, por exemplo.

Em síntese, dialogo sobre possíveis jogos inteligentes de disposição das palavras que ele empregou para comunicar seus achados; procuro identificar algumas séries de

\footnotetext{
${ }^{1}$ Pedagogo. Doutor em Educação pela UFC (2005), mestre em Educação pela UFPB (1998), Especialista em Pesquisa Educacional (1994) e graduado em Pedagogia pela UFPB (1990). Email: erenildojc@gmail.com.
} 
signos que ele acionava; analisar certos procedimentos analíticos com os quais operava e discutir sobre indícios de saberes que mobilizava e produzia, visando identificar, classificar, descrever e explicitar 'as coisas do discurso' na efetividade de sua existência e de suas condições próprias de possibilidade.

Nesse sentido, tomarei, única e exclusivamente, seus escritos, sobretudo alguns produzidos nas décadas de sessenta e de setenta, como fonte de referência e objeto de análise. Em outras palavras, centrado em Foucault, identificarei e selecionarei algumas séries de signos (formulações, frases, afirmações e argumentos) e de coisas efetivamente escritas, anunciadas e produzidas por ele, e, com base nesses achados, explicitarei a noção arqueológica do discurso ${ }^{2}$, com a qual ele trabalhou em vários estudos, análises e pesquisas.

Nesse processo, empreenderei o esforço de, na medida do possível, deixar-me levar por três pressupostos básicos: discutir especificamente sobre a questão do discurso, a partir do primeiro Foucault, isto é, do Foucault arqueológico, que operou com o significado de discurso como enunciado; fazer um exercício reflexivo e analítico arqueológico, sugerido pelo próprio Foucault, percorrendo as camadas do terreno propriamente dito da linguagem e fazendo escavações que possibilitem atingir a zona singular do discurso-enunciado, e ater-me ao movimento argumentativo empreendido pelo próprio Foucault em seus escritos, a fim de poder encontrar neles séries de signos com função de enunciados.

\section{CRÍTICA À ELISÃO DO DISCURSO}

No Resumo dos Cursos do College de France (1970-1982), estão registrados vários temas de interesse investigativo de Foucault. Dentre eles, aparece a problemática do discurso e de suas modalidades, formulada e articulada à noção de prática discursiva, que tratam o discurso como "[...] prática regulamentada dando conta de certo número de enunciados [...]" (1997, p. 90), cujo exercício e inteligibilidade integrariam não somente o cenário da história dos sistemas de pensamento, como também e, sobretudo, o da existência de um nível do dizer, cujas regras de formação seriam constituintes de diferentes ordens discursivas.

\footnotetext{
${ }^{2}$ Como leitura complementar sobre o assunto, sugiro que se leia ALCANTRA, Marcos Angilus Miranda de; CARLOS, Erenildo João. Análise arqueológica do discurso: uma alternativa de investigação na educação de jovens e adultos (EJA). Intersecções (Jundiaí), v. 6, p. 59-73, 2013.
}

\begin{tabular}{|c|c|c|c|c|}
\hline Qevista Oialectus & Ano 4 & n. 11 & Agosto - Dezembro 2017 & p. $176-191$ \\
\hline
\end{tabular}




\section{ACHADOS SOBRE A NOCÃO ARQUEOLÓGICA DO DISCURSO EM...}

Erenildo João Carlos

Com efeito, em seu Resumo dos cursos (1997), Foucault sumariza um plano de trabalho cuja finalidade seria a de escavar esse nível, investigá-lo em diferentes gêneros de pesquisa e discutir sobre ele em seminários e cursos. Nota-se que, nesse escrito, a questão do discurso foi situada no território do domínio dos sistemas de saberes ${ }^{3}$, e o discurso seria produzido, distribuído, posto em circulação e regulado por meio de práticas específicas que colocaria a linguagem para funcionar a partir de regras peculiares, que conferem o aparecimento ou desaparecimento, a inclusão ou a exclusão, o descolamento ou a fixação, a feitura ou destruição e a permanência ou a transformação de determinadas séries de enunciados que são combinadas e articuladas e ganham status numa ordem discursiva singular, produzida para se dizer algo sobre alguma coisa.

No jogo analítico de dizer o que é e não é o discurso, Foucault se posicionou contra sua 'elisão' nas investigações e pesquisas realizadas no campo das humanidades. A expressão 'elisão do discurso' denunciava não somente a submissão de sua existência, de seus perigos e efeitos, mas, sobretudo, a negação da própria existência do discurso como tal. Com efeito, o esforço de navegar contra essa corrente se apresentava na própria indicação do discurso como acontecimento, como prática, como algo que está posto como produtivo, mas, ao mesmo tempo, nem sempre, visto, reconhecido, identificado e considerado.

Foucault analisou a questão do discurso e, em seu entremeio, problematizou a questão da 'elisão da realidade do discurso' no mundo ocidental em sua célebre aula inaugural, proferida em 02 de dezembro de 1970, publicada com o título de A ordem do discurso (2007). Nela, defendeu a hipótese de que as formações societárias ocidentais utilizam 'certo número de procedimentos' e 'temas filosóficos clássicos' como sistemas sociais de sujeição da produção, da circulação e da apropriação do discurso, como espécies de jogos efetivos e regras concretas de controle, seleção e distribuição do discurso.

Sumariamente, pode-se dizer que sua aula foi uma espécie de denúncia sobre um duplo modo articulado de recusa do discurso: de um lado, objetiva-se "[...] conjurar seus poderes e perigos, dominar seu acontecimento aleatório, esquivar sua pesada e temível

\footnotetext{
${ }^{3}$ Veiga-Neto (1995) partilha o entendimento de que o legado de Foucault pode ser situado em três domínios (sistemas de saberes, modalidades de poder e relações de cada um consigo próprio) e que articula três métodos de análise (a arqueológica, a geneológica e a ética). Cf. VEIGA-NETO, Alfredo J. Michel Foucault e educação: há algo de novo sob o céu? In: educação. Porto Alegre: Sulina, 1995. (Org.). Critica pós-estruturalista e
}

\begin{tabular}{|l|l|l|l|l|}
\hline Q ovista Dialectus & Ano 4 & n. 11 & Agosto - Dezembro 2017 & p. $176-191$ \\
\hline
\end{tabular}


materialidade [...]" (Foucault, 2007, p.09); de outro, “[...] responder a esses jogos de limitações e de exclusões e, talvez, também, reforçá-los” (idem, p. 45).

Observamos, portanto, que, ao assumir a cátedra do Colégio de France em 1972, Foucault assinala que, através dos procedimentos de exclusão, silenciamento, rejeição, ocultamento, desvio e indiferença, o discurso não só seria submetido ao controle social, como também, na medida do possível, substituído por algo distinto dele. Por essa razão, seu posicionamento é contundente, ao afirmar que "[...] não mais se relacione o discurso ao solo inicial de uma experiência nem a instância a priori de um conhecimento, mas que nele mesmo o interroguemos sobre as regras de sua formação [...]" (Foucault, 1997, p. 90).

\section{ESCAVANDO O TERRENO DA LINGUAGEM}

No legado de Foucault, encontramos vários escritos dedicados a problematizar a questão do discurso no âmbito da linguagem. Exemplos disso podem ser encontrados em História da Sexualidade I (1999a), As palavras e as Coisas (1999b), Linguagem e Literatura (2001) e A Arqueologia do Saber (2008). Esses textos são referências não só para entender o ser da linguagem (o signo) e o ser do discurso (o enunciado) como também o distanciamento entre eles e o modo arqueológico como Foucault problematizou e analisou o assunto.

Tendo em vista refletir sobre a noção arqueológica do discurso em Foucault, entendo que, inicialmente, precisamos nos ocupar em escavar o terreno da linguagem e refletir sobre o artefato do signo, a partir de alguns pedaços, fragmentos, séries de signos e formulações encontrados em seus escritos.

\subsection{O ser da linguagem: do sinal ao signo}

Como se sabe, a noção de signo tem sido largamente trabalhada e analisada no campo da Linguística, por meio de estudos gramaticais e semânticos, assim como na Semiótica e na Hermenêutica ${ }^{4}$, por meio de estudos interpretativos sobre o sentido, seja ele vinculado ao texto, ao contexto, ao sujeito ou, ainda, a diferentes artefatos culturais. Sobre estes dois últimos campos, esclarece Foucault (1999):

\footnotetext{
${ }^{4}$ Sobre o signo nesses domínios do saber, sugiro as seguintes leituras: SAUSSURE, Ferdinand de. Curso de Linguística Geral. Trad. Antônio Chelini e outros. 12. Ed. São Paulo, SP: Cultrix, 1996; PEIRCE, Charles Sanders. Semiótica. Trad. José Teixeira Coelho Neto. São Paulo, SP: Perspectiva, 2005. 340p; e GADAMER, Hans-Georg. Verdade e método I: traços fundamentais de uma hermenêutica filosófica. Trad. Flávio Paulo Meuer. 12. ed. Petrópolis, RJ: Vozes; Bragança Paulista: Editora Universitária São Francisco, 2012.
}

\begin{tabular}{|c|c|c|c|c|}
\hline Rovista Oialectus & Ano 4 & n. 11 & Agosto - Dezembro 2017 & p. $176-191$ \\
\hline
\end{tabular}


[...] Chamemos hermenêutica ao conjunto de conhecimentos e técnicas que permitem fazer falar os signos e descobrir o sentido; chamemos semiologia ao conjunto de conhecimentos e técnicas que permitem distinguir onde estão os signos, definir o que os constitui como signos, conhecer seus liames e as leis de seu acontecimento [...]. (Foucault, 1999, p. 40).

Sabe-se que esses e outros domínios têm abordado, analisado, descrito, explicitado e empregado o signo e se apropriado dele de diferentes maneiras. No entanto, pode-se dizer que há um entendimento comum em relação ao modo de ser geral do signo, que é apontado, comumente, como aquilo que pomos no lugar de outra coisa, que representa algo que não é ele, mas outro.

O lugar-comum da noção de signo está intrinsecamente associado à ideia de que ele é tudo o que nos remete a alguma coisa, ou seja, a que recorremos para representar, lembrar, referir-se e anunciar algo. Por isso podemos dizer que o signo é algo que se põe no lugar do outro, e cujo ser seria um tipo que não é o que anuncia, refere-se, lembra, representa. É, precisamente, esse modo de existir que torna qualquer coisa possível de se tornar um signo. Assim, a possibilidade de algo não ser a coisa à qual se refere, mas de lembrá-la faz dele signo.

Nessa perspectiva, o signo é sempre signo de algo, que não é nem pode ser signo de si, e cuja existência depende de outra coisa, sem a qual ele não existiria, não teria condição de aparecer como signo. Ele não pode ser idêntico ao que lembra. Por lembrar, difere do que recorda. Referir-se a algo é a condição de que algo possa existir como signo. Anunciar algo é um modo de ser próprio do signo.

Em As palavras e as coisas, Foucault (1999b) constatou que, nos saberes clássicos, essa distinção entre o signo e aquilo a que ele se refere não estava devidamente explicitada e desenvolvida e que havia, na episteme dessa época, uma identificação entre os signos e as coisas. Signo e coisas eram vistos como semelhantes e, por causa disso, foram concebidos como a mesma coisa. Por essa razão, Foucault entendeu que, em vez de signos, seria mais apropriado dizer sinal, já que, em última análise, predominava essa noção na produção, organização e circulação dos saberes vigentes naquele período. Sobre isso, ele assevera (1999, p. 23):

[...] Até o fim do Século XVI, a semelhança desenvolveu um papel construtor no saber da cultura ocidental. Foi ela que, em grande parte, conduziu a exegese e a interpretação dos textos: foi ela que organizou o jogo dos símbolos, permitiu o conhecimento das coisas visíveis e invisíveis, guiou a arte de representá-las.

\begin{tabular}{|c|c|c|c|c|}
\hline Qonista Oialectus & Ano 4 & n. 11 & Agosto - Dezembro 2017 & p. $176-191$ \\
\hline
\end{tabular}


O sinal é algo que pertence à ordem das coisas, do mundo, da realidade, por isso a presença de uma coisa pode indicar a existência de outra, como se, entre os elementos envolvidos e percebidos, houvesse uma relação ontológica de inerência e contiguidade. Como a conexão entre duas ou mais coisas é própria do sinal, a relação de identidade entre as palavras e as coisas, característica predominante dos saberes clássicos, somente poderia ser formulada por ele, não pelo signo. Nesse sentido, informa Foucault (1999):

[...] Nos Séculos XVII e XVIII, [...] a linguagem era um conhecimento, e o conhecimento era, de pleno direito, um discurso. Em relação a todo conhecimento, encontrava-se ela, pois, numa situação fundamental: só se podiam conhecer as coisas do mundo passando por ela. (Foucault, 1999, p. 409).

Certamente, a efetividade do sinal pode ser observada na natureza como uma espécie de relação necessária à existência da matéria e reprodução da vida em geral. ${ }^{5} \mathrm{~A}$ sobrevivência das espécies, por exemplo, seja como gênero ou indivíduo exemplar singular, dependeria da apreensão correta das relações existentes entre as coisas. Uma lebre que não soubesse identificar o cheiro, o movimento e os gestos de um predador seria fácil presa dele. Uma formiga que não soubesse identificar antecipadamente os sinais das mudanças climáticas, como, por exemplo, os dias chuvosos, não subsistiria. Um homem que não soubesse o tempo e o lugar adequado de plantar, colher, caçar e pescar morreria de fome.

O sinal, a vida e a morte se entrelaçam na ordem da vida, e apreendê-los e apropriar-se deles adequada e eficientemente significa, em última instância, aumentar as possibilidades de responder e atender satisfatoriamente às necessidades impostas pelas circunstâncias, pelas situações e pelas experiências existenciais. O sinal seria, nesse sentido, uma estrutura da própria vida que, acessada, apreendida e empregada corretamente, comporia uma espécie de saber necessário à reprodução da vida.

Nota-se que esse modo de entender e construir o saber acerca do mundo é profundamente colado no chão das circunstâncias, das situações e das experiências existenciais e mistura, simultânea e imediatamente, o tempo, o espaço e os acontecimentos. Uma coisa passa a ser ou implicar outra, necessariamente, e a segunda

\footnotetext{
${ }^{5} \mathrm{O}$ enunciado sobre a noção de sinal pode ser aprofundado com a leitura de autores, situados em domínios diferentes do saber. Assim, sugiro consultar: PINTO, Álvaro Vieira. A evolução do conhecimento. Os caracteres do conhecimento científico. In: Ciência e existência: problemas filosóficos da pesquisa científica. 2. Ed. Rio de Janeiro: Paz e Terra, 1979; MORIN, Edgar. O método 3: o conhecimento do conhecimento. Trad. Juremir Machado da Silva. Porto Alegre: Editora Sulina, 1999; e LUKÁCS, György. Prolegômenos para uma ontologia do ser social: questões de princípios para uma ontologia hoje tornada possível. Trad. Lya Luft e Rodnei Nascimento. São Paulo: Boitempo, 2010.
}

\begin{tabular}{|l|l|l|l|l|}
\hline Q Ponista Dialectus & Ano 4 & n. 11 & Agosto - Dezembro 2017 & p. $176-191$ \\
\hline
\end{tabular}


nada mais seria do que a extensão da primeira, ambas ligadas por nexos ontológicos de diferente natureza.

Do ponto de vista da vida humana, desde seus primórdios, as relações de comunicação entre os membros do mesmo grupo social e outros assim como o registro do saber sobre o mundo natural incorporam o sinal como linguagem, cujo funcionamento exigiria sua reprodução, infinitamente replicado através do jogo do pertencimento e de similitudes. "[...] Não há semelhança sem assinalação. O mundo do similar só pode ser um mundo marcado [...]" (Foucault, 1999, p. 36). A análise de registros de alguns desses saberes fez com que Foucault constatasse a existência do dispositivo da assinalação como uma das regras próprias da episteme e do discurso sobre as coisas, ou seja, “[...] o saber das similitudes funda-se na súmula de suas assinalações e na sua decifração [...]" (idem, ibidem).

\subsection{Modos de existir e de funcionar do signo}

Devido à natureza do signo, uma questão diz respeito ao modo como a singularidade de sua constituição possibilita o cumprimento da função de se pôr no lugar do outro. Em outras palavras, como o signo faz lembrar algo ou se refere a algo?

Conforme vimos, o signo pode ser posto no lugar de outra coisa que, geralmente, está ausente, distante ou não é percebida, pois, se assim não fosse, não seria necessário o signo para se lembrar dela ou a ela se referir. Determinada coisa presente não precisa ser lembrada ou referida a partir de outra, a não ser dela mesma, já que estaria diante de nós, mas deveria ser percebida, sentida, vista, ouvida, saboreada, escutada, tocada, utilizada e apropriada. Porém isso só pode ser feito a partir da própria coisa. Não se pode sentir o cheiro da laranja mediante sua fotografia ou seu nome.

Adentrando a reflexão, podemos associar outra indagação à pergunta: “Como o signo faz lembrar algo?": O que signo faz lembrar? Nesse jogo reflexivo e dialético do dizer, nota-se que, de um lado, "o algo" lembrado diz respeito ao objeto da lembrança, que pode ser identificado e nomeado, de forma genérica, de referência, seja ela situada no campo do real ou do imaginário. O referente, nesse sentido, seria, em suma, algo que existe na ordem do mundo da natureza e da vida, ou da cultura e possível de ser comunicado e reconhecido, individual e intersubjetivamente.

Diferente do sinal, a noção de referência não exige que o objeto mencionado esteja, necessariamente, no campo da presença, da percepção, da sensação, do mundo

\begin{tabular}{|c|c|c|c|c|}
\hline Rovista Oialectus & Ano 4 & n. 11 & Agosto - Dezembro 2017 & p. $176-191$ \\
\hline
\end{tabular}


imediato, vivido e cotidiano, já que, ausente, pode ser lembrado. Entretanto, a noção de referência demanda um campo de saber compartilhado, caso contrário, 'o algo' não poderia ser lembrado, referido, mencionado, abordado, tematizado, problematizado, analisado, descrito, comprovado, explicado e discutido.

De outro, 'o como' nos remete a algo existente no signo que possibilitaria o exercício e o acontecimento da lembrança, da menção, da referência. Em outras palavras, o pôr-se no lugar do outro requer um substituto composto de uma inscrição que tenha materialidade empírica e, ao mesmo tempo, esteja associada a uma ideia. Precisamente, seria a combinação arbitrária de uma ideia determinada (significado) com uma inscrição específica (significante), um par epistêmico e discursivo, que permitiria representar-se algo em particular (referência). Portanto, diferentemente do sinal, as ligações entre o significado e o significante e dos dois juntos com a referência não seriam de natureza ontológica, mas arbitrária e convencional.

Considerando a pergunta 'Como o signo faz lembrar algo?', poderíamos abordar o caráter arbitrário e convencional do signo focando nossa atenção nos elementos separados ou em sua unidade. Fiquemos com o exemplo do significante desvinculado do significado. O que utilizaríamos como significante para nos lembrarmos de alguém? Qualquer artefato, natural ou cultural. Por exemplo, como me lembrar da minha esposa ou dos meus filhos? Ora, eu poderia arbitrariamente recorrer a uma situação vivida (o dia do nascimento), a uma fotografia (passeando na orla marítima), a um objeto significativo (um livro presenteado em uma viagem de férias) ou, ainda, a um comportamento desejado (autonomia).

Note-se que os significantes arbitrários mencionados acionam a lembrança de minha esposa e filhos de três maneiras: indicialmente, quando há algo que tem um nexo existencial com eles (nesse caso, o dia do nascimento); iconicamente, quando utilizo algum tipo de imagem visual que possibilite lembrá-los visualmente (como a fotografia do passeio na praia), e simbolicamente, quando aciono algo impregnado de algum significado ou sentido para mim ou para eles (nesse caso, um livro presenteado na viagem e o comportamento desejado de autonomia).

Com esse exemplo, queremos dizer que, no âmbito do funcionamento da linguagem a partir da noção de signo, o que importa não é a arbitrariedade ou a convenção de sua produção como categoria geral da linguagem ou de seus elementos constituintes, mas o que se diz e se pode dizer devido ao saber que se tem, a fim de

\begin{tabular}{|c|c|c|c|c|}
\hline Rovista Dialectus & Ano 4 & n. 11 & Agosto - Dezembro 2017 & p. $176-191$ \\
\hline
\end{tabular}


acionar lembranças do que está ausente.

O objeto sobre o qual se diz alguma coisa só será lembrado ou referido pelo par significante-significado se houver um saber comum sobre eles (significante, significado e referências). Aqui, o saber compartilhado aparece, a um só tempo, com as condições de possibilidade de se entenderem as coisas ditas e a lembrança do objeto referido.

\subsection{A implosão e a dissolução do signo}

A composição tricotômica do signo seria o resultado arbitrário de um modo particular de relacionar o significante, o significado e a referência como constituintes de uma unidade. Combinada de tal maneira, a unidade tricotômica do signo não permitiria, em hipótese nenhuma, pensar o signo de outro modo diferente, como, por exemplo, de forma unitária ou binária. Assim, o paradigma tricotômico sígnico impediria que se concebesse o signo separando ou eliminando algum de seus elementos ontológicos.

A separação ou eliminação de um só elemento do signo geraria a impossibilidade de sua existência, uma espécie de impossibilidade similar à do aparecimento de uma figura geométrica, como a do quadrado, sem algum de seus lados ou ângulos ou sem a ligação entre eles, tal como é próprio a um quadrado: uma unidade geométrica produzida mediante a relação estabelecida entre quatro lados e quatro ângulos iguais. Portanto, sem suas propriedades geométricas singulares, não existe a figura do quadrado, e sem seus constituintes tricotômicos, não existe o artefato cultural do signo.

Diferentemente da impossibilidade de separar ou eliminar seus constituintes, há, no signo, um espaço de aparecimento e deslocamento de diversos pontos de articulação dos elementos que o constituem. Cada ponto ou centro articulador (os vértices do triângulo - significante, significado e referência - ou a composição de pares específicos e possíveis, como significante-significante, significante-significado, significantereferência, significado-significante, significado-significado, significado-referência, referência-significante, referência-significado e referência-referência) pode colocar o signo para funcionar de determinada forma.

Foucault constatou que a soltura dos vínculos constitutivos do signo foi acontecendo, gradativamente, no curso do século passado, devido ao aparecimento da

\begin{tabular}{|c|c|c|c|c|}
\hline Qevista Oialectus & Ano 4 & n. 11 & Agosto - Dezembro 2017 & p. $176-191$ \\
\hline
\end{tabular}


literatura $^{6}$. Sobre isso, ele referiu:

[...] Ora, ao longo de todo o Século XX e até nossos dias ainda [...] a literatura só existiu em sua autonomia, só se desprendeu de qualquer outra linguagem. Por um corte profundo, na medida em que constituiu uma espécie de 'contradiscurso' e remontou assim da função representativa ou da função significante da linguagem àquele ser bruto esquecido desde o final do século XVI. (O grifo é nosso).

$\mathrm{Na}$ composição tricotômica do signo, o significante, livre das amarras fixadas pela arbitrariedade da unidade que o vincula ontologicamente ao significado e à referência, seria o elemento com a condição de operar esse acontecimento. Como marca vazia, seu conteúdo é o nada, por isso pode ser preenchido e relacionado a tudo: a ele mesmo, ao significado ou à referência, individual ou simultaneamente. De acordo com Foucault (1999, p. 61),

[...] a partir do Século XIX, a literatura repõe à luz a linguagem no seu ser: não, porém, tal como ela aparecia no final do Renascimento. Porque agora não há mais aquela palavra primeira, absolutamente inicial, pela qual se achava fundado e limitado o movimento infinito do discurso; doravante a linguagem vai crescer sem começo, sem termo e sem promessa. É o percurso desse espaço que traça, dia a dia, o texto da literatura. ( $\mathrm{O}$ grifo nosso).

Livre de nexos ontológicos e arbitrários, constitutivos, respectivamente, do sinal e do signo, o significante (indicial, icônico ou simbólico) pode aparecer de uma maneira ou de outra: pode significar a verdade ou a mentira; referir-se ao real, ao imaginário ou ao simbólico; circular em diferentes formulações (frase, proposição, atos de fala...); cumprir diversas funções (designar, lembrar, relacionar, ilustrar, mediar, seduzir, encantar, irritar, estimular, inibir, proibir, autorizar...); ser apropriada por domínios específicos (senso comum, filosofia, teologia, ciência...) e correlacionar-se a qualquer ordem discursiva (econômica, política, jurídica, religiosa, educacional, midiática, estética, ética, étnica...). Assim, “[...] crê-se atingir a essência mesma da literatura, interrogando-a não mais ao nível do que ela diz, mas na sua forma significante: fazendo-o, permanece-se no estatuto clássico da linguagem [...]”, assevera Foucault (1999, p. 60).

O aparecimento da Literatura produziu, a um só tempo, a morte na linguagem e fez surgir o que ela tinha de mais essencial - a propriedade arbitrária de ser nada e tudo ao mesmo tempo. $\mathrm{O}$ essencial do ser da linguagem é não ser o objeto que representa. $\mathrm{E}$

\footnotetext{
${ }^{6}$ Esse assunto também foi tradado em outro lugar. Cf. FOUCAULT, Michael. Linguagem e literatura. In: MACHADO, Roberto. Foucault: a Filosofia e a Literatura. 2. ed. Rio de Janeiro: Jorge Zahar Editor, 2001. p. 137-174.
}

\begin{tabular}{|c|c|c|c|c|}
\hline Rovista Oialectus & Ano 4 & n. 11 & Agosto - Dezembro 2017 & p. $176-191$ \\
\hline
\end{tabular}


essa característica possibilitaria que a linguagem fosse o equivalente a tudo. Ora, se podemos dizer que o aparecimento do signo implicou a desconstrução do sinal, ou melhor, da substituição do sinal pelo signo e da manutenção do sinal no signo como referente, similarmente podemos dizer sobre o surgimento do enunciado que foi necessário implodir e dissolver o signo, para que o enunciado fosse produzido e fosse possível a continuidade do signo através da relação.

Como se vê, embora o discurso-enunciado esteja implicado à existência do signo, pelo fato de o aparecimento do primeiro não poder acontecer sem o segundo, eles são distintos. Em outros termos, a evidência de que o signo é uma condição de possibilidade ineliminável do vir a ser do discurso-enunciado não elide o fato de que, embora implicado, eles não têm a mesma natureza, isto é, não são feitos e constituídos do mesmo modo e pelos mesmos elementos.

\section{A EMERGÊNCIA DA NOÇÃO ARQUEOLÓGICA DO DISCURSO- ENUNCIADO}

Em suas pesquisas sobre as modalidades discursivas da loucura, do nascimento da clínica ${ }^{7}$, da sexualidade e das ciências humanas, Foucault se deparou com o discurso como uma espécie de artefato da linguagem, distinto de outros, mas situado no mesmo terreno. Tal constatação indica que o complexo de relações do discurso-enunciado se põe, organiza-se e funciona a partir de um modus operandi para além da inteligibilidade tricotômica do signo. Nesse sentido, pode-se dizer que a escavação empreendida por Foucault trouxe à luz um achado precioso, isto é,

[...] um modo singular que não se poderia confundir com a existência dos signos enquanto elemento de uma língua, nem tampouco com a existência material das marcas que ocupam um fragmento e duram um tempo mais ou menos longo. E esse modo singular de existência, característico de toda serie de signos, desde que seja enunciada, que se trata agora de questionar (FOUCAULT, 2008, p. 99). (O grifo é nosso).

O achado desse 'modo singular de existir, característico de toda a série de signos', exigiu a retomada da análise da problemática do objeto-discurso e do próprio percurso empreendido em suas pesquisas, a fim de explicitar tanto um quanto o outro. Essa pausa para pensar, entender e explicitar o que fizera foi sistematizada no livro A arqueologia do saber (2008). O retorno às pesquisas que efetivou fez com que Foucault, de certo

\footnotetext{
${ }^{7}$ Cf. FOUCAULT, Michael. História da loucura: na idade clássica. Trad. José Teixeira Coelho Neto. 10. ed. São Paulo: Perspectiva, 2014; e Rio de Janeiro: Forense Universitária, 2015. O nascimento da clínica. Trad. Roberto Machado. 7. ed.
}

\begin{tabular}{|c|c|c|c|c|}
\hline Q Ronista Dialectus & Ano 4 & n. 11 & Agosto - Dezembro 2017 & p. $176-191$ \\
\hline
\end{tabular}


modo, identificasse, de um lado, o discurso-enunciado, que faz a linguagem funcionar como condição de possibilidade de seu aparecimento e de sua escansão, e, de outro, que constatasse um modo de elisão do discurso, produzido pelo soterramento da existência do discurso-enunciado no âmbito do próprio terreno da linguagem. ${ }^{8}$ Ou seja, uma espécie de elisão operada pela forma peculiar como os signos funcionam e são abordados pelos domínios clássicos e hegemônicos de então, como, por exemplo, a história das ideias, da Linguística, da Filosofia da Linguagem, da Hermenêutica e da Semiótica.

Em certa medida, para denunciar esses procedimentos de elisão do discurso e anunciar outra possiblidade de entender a vigente, Foucault realizou duas tarefas articuladas e distintas imprescindíveis: uma negativa, que foi a de desconstruir a ideia de que o discurso se identifica com outros artefatos da linguagem, problematizando-o no próprio terreno da linguagem, bem como discutindo o modo de outros domínios e de abordá-lo, como os enfoques forjados a partir “[...] da relação entre o significante e o significado e do nome com o que designa; da relação da frase com o seu sentido ou da relação da proposição com seu referente [...]". Concluindo, devido ao seu exame crítico, “[...] a relação do enunciado com o que enuncia não pode ser superposta a qualquer dessas relações [...]" (Foucault, 2008, p. 100).

Nessa investigação, Foucault diferenciou o discurso-enunciado do que ele não é, ao explicitar suas condições de existir no terreno da linguagem, quer como artefato discursivo próprio, quer como camada da linguagem peculiar às ocupadas, por exemplo, pelos pares significante-significado, frase-sentido e proposição-referente, cujas singularidades coexistem com a singularidade do discurso-enunciado; quer funcionando a partir de regras também próprias, correlacionadas a ordens, práticas e formações discursivas particulares.

Articulada à primeira, a segunda tarefa, de cunho positivo, foi a de conferir visibilidade à camada da linguagem onde se encontraria soterrado o discurso, de escandir sua inteligibilidade, de entender o discurso-enunciado e, consequentemente, apresentar uma alternativa de abordagem distinta das tradicionais: a análise e a descrição de suas condições enunciativas de existência, que ele denominou de arqueológica. Trilhando esse percurso, ele conferiu visibilidade ao tipo específico de relação própria do enunciado, ao dizer:

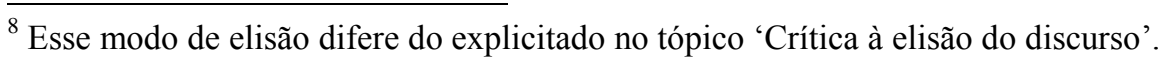

\begin{tabular}{|c|c|c|c|c|}
\hline Rovista Dialectus & Ano 4 & n. 11 & Agosto - Dezembro 2017 & p. $176-191$ \\
\hline
\end{tabular}


[...] Uma série de signos se tornará enunciado com a condição de que tenha com 'outra coisa' (que lhe pode ser estranhamente semelhante e quase idêntica como no exemplo escolhido) uma relação específica que se refira a ela mesma - e não a sua causa nem aos seus elementos. (Foucault, 2008, p. 100). (O grifo é nosso).

No trabalho de escavação da camada do discurso, entranhada no terreno da linguagem, para encontrar nela, e partir dela o discurso em si, seu modo próprio de existir, de funcionar e de operar os signos, Foucault identificou cisões e rupturas, deslocamentos, desconstruções e reorganizações dos elementos constitutivos do signo, bem como o aparecimento da singularidade do funcionamento da linguagem do modo singular discursivo.

Em certo sentido, a emergência do discurso-enunciado encontra-se no bojo da dissolução e da implosão do signo. Desatadas as ligações dos elementos constitutivos da tricotomia, soltos e livres um do outro, seus elementos se encontravam em condições de produzir novas combinações e, consequentemente, novos artefatos e segmentos no terreno da linguagem, como, por exemplo, o artefato-discurso, como enunciado, e a camada arqueológica onde ele se alojou, sedimentando sua existência.

Ora, se a implosão do signo criou a possibilidade de a literatura aparecer, mediante a afirmação do significante como um centro que articula a si mesmo e tudo em torno de si, esse acontecimento também desatou e soltou um elemento presente na composição arbitraria da unidade do signo, não tão visível como o significante, o significado e o referente, os pares sígnicos ou o próprio signo, mas tão importante quanto eles, haja vista que, sem esse outro elemento, a composição tricotômica do signo não seria possível. Refiro-me ao componente da relação, responsável não somente pela combinação e pela tessitura da disposição triádica dos elementos, da centralidade de cada vértice existente em relação uns aos outros e da constituição de diversos pares sígnicos, como também do enunciado. Nesse caso, o centro de articulação da relação seria ela própria, como anunciou Foucault (2008. p. 100), na mencionada passagem que identifica o enunciado como "uma relação específica que se refira a ela mesma - e não, a sua causa, nem a seus elementos".

Note-se que, ao dispensar os elementos do signo (significante, significado e referente) de sua causa (aquilo que ele faz lembrar e a que se refere) e reconhecer a 'relação' como aquilo que faz com que uma série determinada de signo exista como enunciado, o discurso-enunciado não deixa de ter um objeto ao qual se referir, mas o mesmo objeto do signo. O enunciado é signo, ou seja, algo que se põe no lugar de outra

\begin{tabular}{|c|c|c|c|c|}
\hline Q Ronita Dialectus & Ano 4 & n. 11 & Agosto - Dezembro 2017 & p. $176-191$ \\
\hline
\end{tabular}


coisa que não é ela mesma. Foucault (2008, p. 103) refere que

[...] um enunciado não tem diante de si (e numa espécie de conversa) um correlato - ou uma ausência de correlato, assim como uma proposição tem um remetente (ou não), ou como um nome próprio designa um indivíduo (ou ninguém). Está antes ligado a um "referencial" que não e constituído de "coisa", de "fatos", de "realidades", ou de "seres", mas de leis de possibilidade, de regras de existência para os objetos que aí se encontram nomeados, designados ou negados (o grifo é nosso).

Com efeito, diferentemente do signo, o objeto do enunciado é um complexo de relações postas em funcionamento, e, por consequência, autorreferente, ou seja, é enunciado de si. Em outros termos, o que o enunciado menciona, nomeia e faz lembrar constitui-se da mesma coisa que ele é: relações de relações. O enunciado é uma dobra de si, não é algo posto no lugar de outra coisa distinta dele. Ele se põe e põe a si mesmo como objeto.

Nesse horizonte, o que seria posto no jogo específico das relações próprias da função enunciativa? Tudo aquilo a que a ordem discursiva se refere a partir das leis de possibilidade e das regras de existências vinculadas à ordem em questão, como temas determinados (objetos sobre o qual se diz algo), correlatos específicos (conjunto de domínios físicos, espaciais, temporais, ideológicos e epistêmicos), posições de sujeitos singulares (lugar vazio ocupado por qualquer indivíduo) e diferentes materialidades (suporte empírico que serve para registrar uma série de signos qualquer). É o conjunto dessas relações que constitui o enunciado e, simultaneamente, seu referencial. Como explica Foucault (idem, ibidem),

[...] o referencial do enunciado forma o lugar, a condição, o campo de emergência, a instancia de diferenciação dos indivíduos ou dos objetos, dos estados de coisas e das relações que são postas em jogo pelo próprio enunciado; define as possibilidades de aparecimento e de delimitação do que dá a frase seu sentido, a proposição seu valor de verdade (o grifo é nosso).

Ocupando-se da camada arqueológica do terreno da linguagem, lugar onde o signo é posto para funcionar a partir de um complexo de relações de natureza enunciativa, ou seja, de 'leis de possibilidades e regras de existências', Foucault descreve o discurso como enunciado, e este, como um complexo de relações específicas, característico de uma função, não de uma unidade ou estrutura, como, por exemplo, o sintagma, o nome, a palavra, a frase, a proposição, o ato de fala, o texto, a obra e, em última instância, o próprio signo. Nesse sentido, para ele (FOUCAULT, 2008, p. 141-142), o trabalho arqueológico de escavação da camada do discurso consiste em

[...] descrever um conjunto de enunciados, não como a totalidade fechada e pletórica de uma significação, mas como figura lacunar e retalhada; e

\begin{tabular}{|c|c|c|c|c|}
\hline Q Rovita Dialectus & Ano 4 & n. 11 & Agosto - Dezembro 2017 & p. $176-191$ \\
\hline
\end{tabular}


descrever um conjunto de enunciados, não em referência à interioridade de uma intenção, de um pensamento ou de um sujeito, mas segundo a dispersão de uma exterioridade; descrever um conjunto de enunciados para aí reencontrar não o momento ou a marca de origem, mas sim as formas específicas de um acúmulo, não e certamente revelar uma interpretação, descobrir um fundamento, libertar atos constituintes; não é, tampouco, decidir sobre uma racionalidade ou percorrer uma teleologia (o grifo é nosso).

Nesse fragmento, aparecem os artefatos do terreno da linguagem ('figura lacunar e retalhada', 'dispersão de uma exterioridade', 'formas específicas de um acúmulo') que estão ou não ('significação', 'intenção', 'origem') situados no nível enunciativo do discursoenunciado e o modo adequado ('descrever um conjunto de enunciados') ou não ('revelar uma interpretação', 'descobrir um fundamento', 'libertar atos constituintes', 'decidir sobre uma racionalidade' ou 'percorrer uma teleologia') de operar arqueologicamente sua análise. Esse fragmento é um achado exemplar que evidencia um tipo de escavação do terreno da linguagem, de escansão do signo e de análise-descrição do discurso-enunciado, cujo exercício podemos denominar de giro arqueológico.

\section{CONSIDERAÇÕES FINAIS}

Finalizamos este texto assinalando alguns pontos. Em primeiro lugar, consideramos que o giro arqueológico de Foucault viabilizou a crítica da elisão do discurso, também produzida pelo soterramento e pelo esquecimento da camada do discurso; conferiu visibilidade a sua existência, ao problematizar sua singularidade e seu modo próprio de ser e forjou as condições investigativas de identificar, de descrever e de explicitar a especificidade do discurso-enunciado com a produção de dispositivos metodológicos de escavação do nível enunciativo, de escanção do enunciado e de análise de práticas, modalidades e formações discursivas determinadas.

Em segundo lugar, a noção arqueológica do discurso-enunciado apontou um complexo de relações específicas no campo da linguagem, cuja regularidade define as condições efetivas do que se pode dizer, do modo de dizer, de quem pode dizer, de quando e onde dizer algo sobre alguma coisa.

Em terceiro lugar, a regularidade da presença de relações e correlações específicas constitui uma prática discursiva determinada, produtora de certas ordens de discurso. Do ponto de vista geral, pode-se entender a prática discursiva como "[...] um conjunto de regras anônimas, históricas, sempre determinadas no tempo e no espaço, que definiram, em uma dada época e para certa área social, econômica, geográfica e linguística, as condições de exercício da função enunciativa [...]” (Foucault, 2008, 133).

\begin{tabular}{|l|l|l|l|l|}
\hline Q Povista Dialectus & Ano 4 & n. 11 & Agosto - Dezembro 2017 & p. 176 - 191 \\
\hline
\end{tabular}


Em quarto lugar, o discurso entendido como enunciado caracteriza-se como uma maneira determinada de ordenar os saberes disponíveis, acionados por meio das regras de relações estabelecidas, vigentes e possíveis no seio da prática e das formações discursiva em questão.

Em quinto lugar, pode-se dizer que a revisão empreendida por Foucault proporcionou ao campo das ciências humanas e sociais uma rica fonte de saberes e conhecimentos sobre o terreno da linguagem, o discurso-enunciado e a indicação de ferramentas teórico-metodológicas para pesquisa, estudos, reflexões e problematizações sobre ambas as questões e suas interfaces.

Em sexto lugar, o resultado das pesquisas efetuadas por Foucault, os procedimentos de análise e descrição do discurso, as noções-chaves produzidas, os temas e os objetos pertencentes ao nível enunciativo, os problemas, as hipóteses e as teses que podem ser formuladas a partir do campo enunciativo sobre a linguagem, em geral, e o discurso, em particular, constituem um legado rico de possibilidades para se acolher a Análise Arqueológica do Discurso como uma teoria do discurso.

Por fim, o fato de nos depararmos com a regularidade da questão do discurso na dispersão e na descontinuidade de seus escritos indica que Foucault quis trazê-lo à luz, expor sua nudez e conferir-lhe visibilidade e existência. Esse trabalho, indubitavelmente, configurou-se como uma de suas atividades mais fecundas, cujos achados podem ser encontrados nos registros da vasta produção que deixou.

\section{REFERÊNCIAS}

FOUCAULT, Michel. Resumo dos Cursos do College de France (1970-1982). Trad. Andrea Daher. Rio de Janeiro: Jorge Zahar Editor, 1997.

A incitação aos discursos. In: História da sexualidade: a vontade de saber, n. 1, 13. ed., Rio de Janeiro: Graal, 1999a. p. 21-36.

Fontes, 1999b.

As palavras e as coisas. Trad. Salma Tannus Muchail. 8. ed. São Paulo: Martins . Linguagem e literatura. In: MACHADO, Roberto. Foucault: a Filosofia e a Literatura. 2. ed. Rio de Janeiro: Jorge Zahar Editor, 2001. p. 137-174.

A ordem do discurso. Trad. Laura Fraga de Almeida Sampaio. 15. ed., São Paulo: Edições Loyola, 2007.

A arqueologia do saber. Trad. Luiz Felipe Baeta Neves. 7. ed. Rio de Janeiro: Forense Universitária, 2008.

\begin{tabular}{|c|c|c|c|c|}
\hline Qevista Dialectus & Ano 4 & n. 11 & Agosto - Dezembro 2017 & p. $176-191$ \\
\hline
\end{tabular}

